\title{
LA EXPANSION URBANA COMO REVELADORA DE TERRITORIALIDADES: \\ CONFLICTO DE PROXIMIDAD EN USME-BOGOTÁ
}

URBAN SPRAWL IS A GENERATOR OF TERRITORIALITY:

THE CONFLICT IN USME-BOGOTÁ

v. 8, n. 3 [14]

set/dez (2016)

Artigo
Aureliano Camacho Bonilla

Universidad de Paris Ouest Nanterre

aurecamacho@yahoo.com

\section{Resumen}

El presente artículo es el resultado parcial de la investigación del Doctorado en Urbanismo y ordenamiento del espacio que llevo a cabo actualmente en la Universidad Paris Ouest Nanterre. El objetivo es analizar el conflicto generado por la decisión de actores públicos y privados de desarrollar proyectos de vivienda de interés social, en un espacio de frontera rural-urbano o espacio periurbano de Bogotá (Usme), en donde conjugan e interactúan diversos actores. Se trata de mostrar como el conflicto resulta una forma de crear nuevas territorialidades y así mismo como proceso, es revelador de nuevas identidades territoriales que conducen a reflexionar sobre la relación entre la sociedad y el espacio.

\section{Palabras claves}

Conflicto, expansión, identidad, territorialidad

\begin{abstract}
This paper brings partial results of the doctoral research in urban planning and management of the space currently conducted at the University Paris Ouest Nanterre. The aim is to analyze the conflict generated by the decision of public and private stakeholders to develop projects of social housing, in an area of rural-urban border where various actors combine and interact. It is about to show how the conflict is a generator of territoriality, and likewise as a process, is revealing new territorial identities that lead us to reflect on the relationship between society and space.
\end{abstract}

\section{Keywords}

conflict, identity, territoriality 


\section{Introducción}

En las páginas que siguen se analiza el conflicto generado por la decisión de actores públicos y privados de desarrollar proyectos de vivienda de interés social ${ }^{1}$, para las familias más desfavorecidas de la ciudad. El caso de Usme resulta interesante porque es una ilustración de los efectos y consecuencias de los procesos de transformación urbana sobre un espacio en particular. En efecto, se trata de un espacio de frontera o espacio periurbano en donde conjugan e interactúan diversos actores: los campesinos de la zona rural, los habitantes nativos del pueblo de Usme, los viejos habitantes de urbanizaciones construidas hace más de una década y los nuevos habitantes de urbanizaciones más recientes.

Usme es una de las 21 localidades en las que se divide la ciudad de Bogotá. Ubicada al sur-oriente de la capital, esta localidad presenta características particulares respecto a las demás. De su superficie total de 21. 556,16 hectáreas el $85 \%$ equivalen a suelo rural, presentando entonces una importante zona de borde rural-urbano que conserva evidentemente rasgos considerables de ruralidad, confluyendo elementos culturales, productivos y simbólicos que presentan una dinámica continua de expansión, crecimiento, ocupación y conflicto gestada por los actores que interactúan en este territorio: sociales y comunitarios, institucionales, públicos y privados. En esta localidad según estadísticas de la alcaldía habitan alrededor de 400.000 habitantes que hacen parte en su mayoría de los estratos 1 y 2 , que según el sistema de estratificación colombiano son los grupos sociales más desfavorecidos. En nuestra zona de estudio se sitúa el antiguo pueblo de Usme, cuya historia se remonta a la época colonial. Muchas de las familias que habitan en Usme-Pueblo se consideran parte de una comunidad fundada sobre el trabajo y la cultura de la tierra. A pesar de estar en contacto con la ciudad desde su incorporación como localidad en 1971, es solamente en las dos últimas décadas que se han visto "invadidos" por habitantes y familias que han venido a la zona a través de programas de vivienda. Sin embargo, es a partir de los últimos tres años que han llegado más familias debido a una política de vivienda tanto del gobierno nacional como distrital, de esa manera el conflicto en Usme toma matices más agudos.

El análisis de la situación de conflicto en Usme permite exponer la hipótesis y a la vez abordar uno de los ejes conductores de la investigación de doctorado que desarrolló en este momento. Se trata de mostrar como el conflicto resulta una forma de crear nuevas territorialidades y así mismo como proceso es revelador de nuevas identidades territoriales que nos hablan de la relación entre la sociedad y el espacio. Si hablamos de identidad nos referimos a la manera como los actores elaboran un anclaje al espacio, determinado por el conjunto de percepciones y representaciones socio espaciales que se van desarrollando durante el conflicto.

\footnotetext{
${ }^{1}$ La vivienda de interes social (VIS) es aquella que se desarrolla para garantizar el derecho a la vivienda de los hogares de menos ingresos. Hace parte de toda una política de financiamiento que a través del ahorro y de créditos hipotecarios busca facilitar su adquisición.
}

(c) Urbana: Rev. Eletrônica Cent. Interdiscip. Estud. Cid Campinas (SP)

v.8, n.3 [14] p.133-148 ISSN 1982-0569


El conflicto no puede ser comprendido independientemente de la relación que los habitantes tejen con el espacio a través de sus prácticas cotidianas, así mismo estas prácticas se revelan en diversas situaciones de tensión, de defensa y de reapropiación. Se trata aquí de exponer algunos ejemplos y situaciones en donde un conflicto de proximidad es generador de espacios de negociación y representación.

En efecto, los conflictos de proximidad como hemos decidido utilizarlo en este artículo "describen las situaciones que ponen en juego los residentes por el control de su espacio próximo" 2 Por proximidad comprendemos todo proyecto, actividad o práctica que afecta directamente el espacio o medioambiente de un grupo social. Esta definición se corroboró a partir de las primeras observaciones de campo, en las que los habitantes manifestaban las situaciones de conflicto y tensión por sentir la proximidad de un proyecto de vivienda; posteriormente serían los conflictos con otros grupos instalados en las proximidades de lo que ellos consideran nuestro espacio. Justamente el nombrar y valorar el espacio (nuestro), manifiesta como a partir del conflicto los habitantes efectúan una re-definición de su inscripción espacial y territorial.

Precisamente en esa inscripción los grupos son conscientes de los factores sociales y culturales comunes que la componen, de esa manera van creando solidaridades y reconocimientos entre sí, pero también diferencias y puntos en desacuerdo que revelan la posición de los actores implicados. La posición de los actores o grupos movilizados se revela a partir de la apropiación material y simbólica del espacio, de su constante valoración y nominación (nuestro). "Los habitantes movilizados sitúan antes que nada, por defender su posición, las calidades y valores del espacio en cuestión, efectuando de ese modo un trabajo de producción de una cierta representación de su espacio residencial."(Melé, 2013). Para nuestro estudio de caso, la irrupción de un proyecto de transformación del espacio como la construcción de una serie de urbanizaciones, resulta un elemento activador de un conflicto que amenaza la organización de un territorio, apropiado e identificado por un grupo social, por consiguiente este hecho particular suscita una reapropiación de su espacio de vida, una valorización de los atributos territoriales de ese espacio de vida y de esa manera poder legitimar sus acciones de defensa e intervenir en la arena pública.

Así mismo, un hecho espacial tiene por efecto crear vínculos sociales entre habitantes, colectivos y asociaciones que ponen en marcha una acción colectiva con un fuerte principio espacial que se manifiesta a través del proceso de territorializacion. La geografía social define la territorializacion como un doble movimiento de apropiación material e ideal de una porción de espacio por un grupo social (Di Méo, 1998). Esta apropiación hace parte de la construcción de su identidad territorial, construcción que resulta crucial para la defensa del territorio.

\footnotetext{
${ }^{2}$ Bourdin et Melé en Conflits de proximité et dynamiques urbaines, bajo la dirección de Patrice Melé, Editorial Presses Universitaires de Rennes, 2013 
Por otra parte, el proceso de territorializacion no puede ser exclusivamente relacionado a una oposición unilateral de los residentes contra un proyecto particular. Es importante afirmar que existen situaciones de conflicto entre los diferentes grupos que ponen en cuestión la noción de interés general o bien común, cada actor puede adoptar su posición respecto a las consecuencias de una decisión y sentirse afectados de manera diferente, sin que haya una comunión de intereses. Surgen entonces diversas situaciones dentro del conflicto como la interacción, la negociación, el intercambio o la concertación, enriqueciendo de esa manera el análisis de los conflictos territoriales. No se trata de identificar solamente el conflicto, sus causas o efectos, el interés se centra mejor en comprender el conflicto como fuente de acciones colectivas que apuntan a repensar la noción de ciudadano que participa en la toma de decisiones.

El presentó artículo está organizado en tres partes. Inicialmente, expongo un marco general del conflicto que se ha desarrollado en las periferias de la ciudad de Bogotá, abordando también de manera abreviada las características históricas y la lógica que subyace en la constitución de estos espacios. En la segunda parte, abordo el caso particular de un proyecto urbanístico de viviendas construido en la periferia sur de Bogotá y en particular en una zona de expansión urbana. Este estudio de caso, (operación urbanística Nuevo Usme) ejemplifica la agudización del conflicto generado por el crecimiento de la ciudad en una zona periurbana definida por las tensiones y confrontaciones entre diversos actores, focalizándonos en el estudio de los mecanismos de oposición y movilización de las comunidades en defensa de su territorio. En efecto, en la última parte abordamos el concepto de Borde Sur de la ciudad, como una forma de defensa y reapropiación del territorio por parte de diversas organizaciones, ilustrando así las nuevas formas de territorialidad que se han generado durante el conflicto.

La información que condesamos en este artículo, obedece a dos etapas de campo de seis meses, cada una, desarrolladas la primera en el año 2014 y la segunda durante el primer semestre del ano 2016. En el trabajo de campo se utilizó la observación participante y las entrevistas en profundidad y entrevistas semiestructuradas como herramientas metodológicas fundamentales. Así mismo, enfatizamos las entrevistas con líderes de la zona rural y de la zona urbana, (50 entrevistas en total), asistimos a reuniones, comités y asambleas en barrios y veredas que nos permitieron recoger las percepciones de los habitantes sobre el conflicto. Esta información de campo se complementó con una revisión exhaustiva de documentos institucionales que han descrito y profundizado sobre los conflictos en la periferia sur de la capital. Igualmente se hicieron una serie de entrevistas a funcionarios y personas de las instituciones que han estado en los procesos de mediación y concertación entre los actores.

\section{Contexto histórico de una ciudad segmentada}


A partir de los años 1990 los conflictos ligados al desarrollo de proyectos de vivienda en el sur de Bogotá, han implicado la respuesta de una serie de colectivos movilizados contra lo que ellos consideran las consecuencias negativas de un proceso histórico de urbanización segmentada, que ha determinado una fisionomía de la ciudad diferenciada y polarizada. Un eje Centro-Norte de la ciudad que se ha consolidado como la principal zona residencial para estratos medios y altos. Del otro lado, un eje sur pobre donde a partir de la segunda mitad de siglo XX se asentó la clase obrera y las familias que llegaban a la ciudad producto del proceso de migración rural-urbano. Fue en el sur de la ciudad donde principalmente se establecieron desarrollos de origen informal y procesos de autoconstrucción que han aportado un importante peso a la expansión de la ciudad.

Así como en Angosta la capital ficticia que recrea el escritor Héctor Abad Faciolince, en donde la ciudad está dividida por sectores, áreas de exclusión y una política de apartamiento que es construida históricamente por la elite "la ciudad no se dividió de un día para otro; ya, en parte, había nacido separada por la geografía y por la riqueza de los habitantes de los distintos sitios" (Abad Faciolince, 2003). Nuestro apartheid urbano tanto en Angosta como en Bogotá y la ciudad Latinoamericana ilustrada por José Luis Romero (Romero, 1986), revela una concepción política del modelo de ciudad que hasta nuestros días se ha construido, y una forma de concebir nuestra realidad social urbana.

Una de las explicaciones de este fenómeno de diferenciación y polarización de la ciudad se puede rastrear desde la década de los cincuenta, momento en el cual las decisiones de la acción pública en coalición con los promotores inmobiliarios buscaron privilegiar tan solo ciertos sectores de la ciudad. Los dueños y comercializadores del suelo planifican donde realizar las intervenciones urbanísticas, de esa manera una estructura residencial con mejores condiciones de habitabilidad, optimas vías de acceso y espacio público fue reforzando las diferencias socio espaciales de la ciudad.

Paralelamente a la consolidación de este segmento privilegiado de la ciudad, se iba fortaleciendo la hegemonía del mercado inmobiliario y su control en las intervenciones. Sin embargo, la administración de la ciudad se enfrentaba a un crecimiento desmesurado y espontáneo en el sur, al igual que una fuerte demanda de vivienda y mejores condiciones de habitabilidad por parte de los grupos más desfavorecidos En este contexto, y como una forma de resolver estos problemas, en 1954 algunos municipios aledaños a Bogotá como Usme, Fontibón, Bosa y Usaquén fueron añadidos de manera arbitraria a la ciudad. Lo que siguió a continuación han sido intentos de las diferentes administraciones por controlar la expansión urbana, articular los desarrollos informales existentes y formular una planificación de la ciudad. Sin embargo, las medidas acuerdos y normas han resultado infructuosas. Entre 1971 y 1991 el suelo "clandestino" representaba el 39\% del crecimiento urbano, alojando a casi el 30\% del crecimiento poblacional de Bogotá. (Alfonso Roa, 2012); La autoconstrucción como mecanismo de producción informal de vivienda ocupó alrededor del 44\% en el último periodo intercensal (19932005), cifra significativa que no se presentaba desde los años setenta. 
Este panorama dramático y el considerable aumento de las prácticas informales de acceso al suelo, están ligadas directamente al establecimiento de la lógica neoliberal que en Colombia se instaló como en otros países de Latinoamérica a principios de los años noventa y que se formalizó durante la constitución de 1991. Para la ciudad, esta lógica significa que la acción pública toma las decisiones sobre las políticas que la orientan, pero reduce su campo de incidencia en las intervenciones urbanísticas, jugando un rol de regulador y facilitador de las inversiones privadas. Este paradigma privatista adopta la lógica del mercado como organizador de la vida social y política, opacando otras dinámicas sociales y culturales que no resultan rentables.

En un contexto capitalista globalizado los gobiernos se convierten en proveedores de servicios, los ciudadanos en "clientes" o usuarios y las ciudades como señala Harvey "se convierten en espacios claves de crecimiento económico donde los agentes públicos y privados actúan como verdaderos promotores de ésta a través del espacio urbano, configurando una lógica empresarial de gobernanza urbana" (Harvey, 1993)

Bogotá se inscribe durante la década de los noventa dentro de un proceso de renovación de la gobernanza urbana (Lulle, 2004) que sentaría los fundamentos de un nuevo modelo de planificación. En primer lugar, el nuevo modelo reposa sobre el principio de reforzar la capacidad de la acción pública en la transformación de los territorios, es decir regular las intervenciones públicas y privadas orientándolas hacia el cumplimiento de objetivos económicos y sociales. Por esta razón se favoriza la concertación o alianza público -privada en el ámbito de grandes intervenciones espaciales. Diversos instrumentos fueron creados bajo esta perspectiva: planes parciales, macro proyectos, operaciones estratégicas. La adquisición y expropiación de tierras para este tipo de operaciones, al igual que para la construcción de infraestructuras, es sustentada y reforzada por un nuevo cuadro legislativo.

En 1998 se formula el primer plan de ordenamiento territorial POT que concluye con su adopción definitiva en el año 2000. El punto de partida del POT fue una estadística derivada de los estudios de la época sobre el proceso de metropolización: En 2010 la ciudad contaría con 1,8 millones más de habitantes, hecho que debería proveer 500.000 viviendas de las cuales el $80 \%$ estarían dirigidas para los estratos socioeconómicos bajos y medio-bajos. Desde ese momento se inicia una aguda polémica, sobre la delimitación de zonas de expansión urbana, revelando dos modelos de ciudad, y por consiguiente debates entre los partidarios de una ciudad compacta y densificada o ciertos sectores (promotores) inclinados por una ciudad en continuo crecimiento hacia sus periferias.

Este conflicto simboliza un modelo de ciudad donde han reinado los propietarios de tierras y los promotores inmobiliarios, quienes han sometido al espacio desde su lógica mercantilista. Por otro lado, encontramos una ambición institucional de controlar el crecimiento urbano, cambiar la acción pública local y romper con la lógica rentística y especulativa anterior, 
poniendo en marcha una lógica de desarrollo urbana regulada por el estado con el objetivo de construir una ciudad colectiva que promueva la competitividad y la equidad.

A continuación presentamos nuestro estudio de caso. Se trata de uno de los proyectos urbanísticos más grandes de Bogotá que se desarrolla en la zona de expansión de la localidad de Usme $^{3}$, una de las localidades con mayor área de suelo rural que por esta razón ha sido escenario de conflicto entre visiones de un modelo de ciudad difusa y en crecimiento o el modelo de ciudad compacta.

\section{La operación urbanística Nuevo Usme: reveladora de territorialidades.}

La operación estratégica Nuevo Usme constituye un proyecto de gran envergadura que tiene como objetivo frenar el urbanismo informal en la franja de transición urbano/rural del sur de la ciudad. Se trata de un espacio complejo alrededor del núcleo geográfico del pueblo de Usme, profundamente marcado por su carácter rural y sometido a intensas presiones debido a la especulación de tierras ejercida por los urbanizadores-piratas que han construido de manera informal los espacios urbanos contiguos. Este proyecto que cuenta con 910 hectáreas representa uno de los grandes retos del gobierno de Bogotá, en la medida en que es una de las principales zonas de expansión definidas por el POT, constituyendo una significativa oportunidad para disminuir el histórico déficit de vivienda. Nuevo Usme tiene por objetivo generar una oferta de vivienda (se disponen de 55000 unidades habitacionales para 220000 habitantes), para la población de más bajos recursos que generalmente recurren al mercado informal. Otro de los objetivos es la utilización de instrumentos de planificación y gestión urbana para controlar los fraccionamientos ilegales en la zona.

La historia del proyecto se remonta al año 2003 cuando inician los trabajos de diagnóstico, formulación y negociación con la población campesina. Es necesario resaltar que la operación estratégica "Nuevo Usme" está coordinada y ejecutada por Metrovivienda, una empresa pública que funciona como promotora de proyectos de vivienda. Esta empresa constituida como uno de los actores más importantes dentro del contexto conflictual de Usme, tiene el objetivo de comprar tierras rurales, urbanizarlas y venderlas a bajo precio a los constructores privados con el fin de construir viviendas de interés social. Desde esta lógica, el Estado, -en este caso el Distrito de Bogotá-, compra o indemniza los bienes inmobiliarios y las tierras partiendo de una base de valores comerciales muy baja. Así pues, el Estado por responder al interés colectivo que supuestamente prima en la ejecución de los proyectos, no está en la medida de compensar y retribuir con una vivienda equivalente a las familias que se ven

\footnotetext{
${ }^{3}$ La ciudad de Bogotá está dividida oficialmente en veinte localidades que contiene según el decreto 190 de 2004 diferentes tipos de suelo : suelo urbano, suelo rural y suelo de expansion. La Localidad 5 de Usme, ubicada en el costado suroriental de la ciudad de Bogotá, cuenta con un área total de 21.506,64 Ha, de la cuales pertenecen al área rural $18.483,83 \mathrm{Ha}$, es decir el $85.94 \%$.

(c) Urbana: Rev. Eletrônica Cent. Interdiscip. Estud. Cid 
afectadas. Por otro lado, una indemnización basada exclusivamente sobre el precio de la propiedad, y no sobre el precio requerido por las familias para comprar otra vivienda, resulta excluyente sobre todo para los pequeños propietarios que no se ven integrados a la dinámica de transformación territorial de la zona, viéndose obligados a irse a otras zonas de la ciudad. Para muchos de los habitantes entrevistados esta "dolorosa partida", resulta el desmembramiento del tejido social, cultural y profesional construido durante anos.

Durante la primera fase de divulgación del proyecto, uno de los primeros malestares se concentró como lo mencionamos en el problema de las indemnizaciones. Sin embargo, antes de la fase de socialización del proyecto, la zona limítrofe rural/urbana de la localidad de Usme ha tenido que resistir desde la década de los noventa la fuerte presión de algunos actores para obligar a vender a los campesinos, así como afirma una líder de la vereda Los Soches, una de las más afectadas por la expansión urbana, "Todo empezó en el año 1993, los primeros afectados fuimos los habitantes de los Soches, La estrategia del Distrito en aquella época era subirle los impuestos al predial y obligar de esa manera a vender las tierras. Por otro lado estaba sin control la urbanización pirata que también apretaba" (Entrevista No 10).

Los Soches representan una de las principales formas de organización campesina que defendió el territorio desde los albores del conflicto. Constituye una de las "estrategias-ejemplo" como muchos lo evocan que surge claramente desde la reivindicación de una identidad campesina, "una cultura campesina a valorar". El proyecto Agroparque los Soches como se bautizó desde 1993 es una organización social que tiene como objetivo la preservación del medioambiente y la defensa de la cultura campesina a través de la promoción del ecoturismo y el agroturismo como alternativas económicas y sostenibles ${ }^{4}$. A través de una serie de decretos como el 06 de 1990, el concejo de Bogotá declaró la vereda de Los Soches (entre otras) como zona de expansión urbana, proponiendo un cambio de uso del suelo rural a suelo urbano que los condenaba a ser una zona más de borde con miras a ser construida. En 1996 Los Soches retoman de nuevo el status de suelo rural, presentan un modelo alternativo de manejo y conservación de las áreas rurales y paralelamente logran detener la expansión.

El ejemplo anteriormente citado marca una de las primeras situaciones de territorializacion del conflicto que va a sentar precedentes en los sucesos que posteriormente se desarrollarían. El hecho de detener la expansión y evitar la realización de proyectos de vivienda, provocó una serie de reacciones de otras asociaciones que si bien no fueron inmediatas como era de esperar, lograron reconsiderar de nuevo la dimensión territorial del conflicto. Así mismo, a nivel local el ejemplo Soches condujo a una dinamización de las relaciones entre Usme y el

${ }^{4}$ Agroparque Los Soches. http://www.bogotaturismo.gov.co/agroparque-los-soches, Recuperado el 26 de Abril de 2014. 
territorio, dinamización que traería consigo una valoración simbólica y material de la tierra como lo veremos a continuación.

Si bien existió un precedente de resistencia como lo fue y lo es Los Soches, fue hasta el 2003 que se concretiza la acción territorial local por parte de otras asociaciones. Como lo mencionamos, fue la llegada del proyecto Nuevo Usme la que suscita muchas reacciones: "empiezan a brotar muchas asociaciones y movimientos, también se fortalecen estrategias como Los Soches y se empiezan a construir una contrapropuesta" (Entrevista No 1).

Para muchos campesinos y habitantes el proyecto Nuevo Usme hace su aparición por primera vez a partir de una estrategia publicitaria patrocinada por la empresa Metrovivienda, que buscaba visibilizar las ventajas del proyecto. Fue a través de vallas y anuncios localizados en puntos clave de la localidad, que se explotó la imagen apacible y tranquila que genera habitar en un apartamento cerca de la naturaleza y con áreas verdes para las familias. Igualmente, el anuncio de rutas de transporte, mejoras en las vías y una dotación de equipamientos irían de la mano de las viviendas. Dentro de la misma etapa de presentación de Nuevo Usme, la estrategia de la empresa era a través de sus visitas, impulsar a los propietarios a vender la tierra a bajo costo, aprovechándose del discurso generalizado de una ruralidad empobrecida y sin esperanza, jugando también con la imagen de un futuro económicamente promisorio y socialmente más adecuado en alguna otra zona de la ciudad.

Mientras que la publicidad hacía presencia en calles y esquinas de Usme, en los escenarios de participación local se asistía a la discusión de las primeras inquietudes que marcarían todo el desarrollo del conflicto: ¿cuáles son los límites o bordes de la ciudad? y ¿de qué manera se puede generar un desarrollo territorial incluyente de Usme y sus habitantes?

\section{El Borde Sur de Bogotá: Mas allá de un concepto, una forma de defensa}

Más que responder a la pregunta sobre los límites de la ciudad, lo que resulta interesante son los procesos por los cuales se llegó a hablar y a plantear un concepto como el de Borde sur de la ciudad, concepto que tiene toda una carga histórica, simbólica y factual de la reapropiación de un territorio por la comunidad. Constituye en efecto uno de los logros más remarcables del conflicto en su aspecto territorial.

Cuando hablamos de "borde de la ciudad", debemos remontarnos a las primeras experiencias participativas en Usme, como lo fueron Los Soches que mencionamos anteriormente. En el seno de esta comunidad campesina "se empezó a hacer tránsito de un imaginario en términos de predio a un imaginario en términos de territorio, entendiendo -los campesinos- que había un tema colectivo que estaba sin pensarse, y que efectivamente se aceptaba la exclusión cada cual desde su posición" (Entrevista No 10). Entonces surge otra lógica 
para leer el territorio cuando comprendimos que la lógica urbanística estaba cimentada en la propiedad privada y no en la territorialidad" como afirma una líder rural. Esta territorialidad se materializa cuando algunas organizaciones campesinas a través del concepto de borde logran construir el primer plan de ordenamiento que reconoce a la vereda Los Soches y el parque Entrenubes como zona rural de borde y modelo alternativo de ocupación del territorio. Gracias a las labores conjuntas de organizaciones e institución, no solo se establecieron normas urbanísticas que detuvieron en su momento las ambiciones expansivas de promotores privados y urbanizadores piratas; además desde el concepto de Borde cambió la perspectiva sobre la propiedad y su función social y ecológica. En ese sentido respecto a la dimensión jurídica del territorio, el Borde Sur sentó un precedente para la cimentación de la ley 388 de 1997, una de las más importantes para el país porque definió las herramientas de gestión y planificación de las ciudades, limitando la acción de los particulares sobre el espacio urbano en nombre del interés colectivo.

Observar el Borde como una situación de territorialidad suscitada por el conflicto, nos revela la gran capacidad de los actores implicados no solo por definir y nombrar el territorio, sino también concretizándolo y reglamentándolo de manera coherente con sus nuevas perspectivas. Así mismo, muestra como los actores locales logran a partir de un conocimiento de las normas urbanísticas y los estatutos de diversas instituciones, modificarlas y adaptarlas a sus exigencias particulares. Detrás de estas primeras conquistas encontramos el ingreso del conflicto dentro de un universo jurídico que sirvió en un principio como herramienta de información de los campesinos sobre las posibles normas que hayan sido susceptibles de ser violadas. En el caso del borde y posteriormente de las expropiaciones, los derechos de petición como figura jurídica para solicitar o reclamar frente a las autoridades públicas, se convirtieron en herramientas que dejaban sin efecto los decretos hasta que se examinaran a profundidad.

"La asistencia jurídica" como testimoniaba un campesino (entrevista No 13) resultó tener repercusiones importantes en la zona de conflicto y sus alrededores. Los mecanismos tales como resoluciones y pactos, gracias a los cuales los campesinos principalmente pudieron evitar la expansión y la expropiación, han constituido un cambio en la naturaleza de la territorialidad. No es raro encontrar personas que sostienen que han sido los procedimientos jurídicos y no la movilización que han frenado las intenciones de ciertos sectores del gobierno de Bogotá.

Como consecuencia de la utilización de estas acciones jurídicas, las comunidades ganan cierta confianza en su accionar y deciden construir propuestas mucho más específicas en términos territoriales, solicitando con mayor contundencia espacios de discusión con los actores institucionales. En efecto el llamado "Pacto de Borde" surge como una herramienta participativa que desde el año 2006 ha tratado de definir compromisos y acciones a desarrollar por parte de las comunidades asentadas en la zona de expansión y las instituciones. El pacto ha obrado como un instrumento que facilita la participación de los ciudadanos, generando un escenario de 
interlocución entre los actores implicados, y manteniendo el eje conductor que ha sido la defensa del territorio, la preservación y conservación medioambiental y la resolución del conflicto.

Fue precisamente en este contexto que surgió la "Mesa de Concertación campesina" que actualmente reúne en su mayoría a los líderes y representantes de las diferentes veredas que conforman la zona rural de Usme. La mesa representa una forma concreta de producción de un espacio público político por parte de las comunidades, de la mano igualmente de una institucionalización del conflicto que desde los pactos de borde ha significado el establecimiento de una palestra institucional específica, promovida por las organizaciones campesinas y seguida por algunas instituciones como la CAR (Corporación Autónoma Regional) y las secretarias de Hábitat y Medioambiente de Bogotá. Su objetivo ha sido principalmente la definición de los planes parciales territoriales y los polígonos que contiene el proyecto. Por planes y polígonos comprendemos los instrumentos de planificación y gestión territorial que particularizan las necesidades de cada sector en donde se actúa.

En materia de participación uno de los acuerdos más significativos de la mesa de concertación fue redefinir el programa de reasentamiento productivo que hace parte de uno de los planes parciales del proyecto Nuevo Usme ${ }^{5}$. El programa se dirigía a los agricultores que se encontraban en una zona que prevé ser completamente urbanizada. Un acuerdo entre la administración y las organizaciones sociales permitió que los campesinos de vida urbana lograran ser incorporados al programa y si lo deseaban ser reasentados. Este acuerdo le permitió a muchas organizaciones populares de Usme fortalecerse y al mismo tiempo reforzar su discurso y sus acciones sobre otras problemáticas que afectan el territorio como la extracción minera y la contaminación del rio Tunjuelito ${ }^{6}$.

El hecho de desplazar el eje de debate de la expansión a otros conflictos específicos resulta importante en la medida en que se ha ido construyendo progresivamente una visión colectiva del territorio y de sus necesidades. Ha sido en torno a la mesa como espacio de confrontación y discusión que se han expuesto algunos intereses territoriales que han favorecido a otras organizaciones con sensibilidades diferentes pero con puntos en común: una asociación de jóvenes ecologistas, asociación vecinal por defensa del rio, asamblea de convivencia, Red de agricultores urbanos de Usme...en este sentido las asociaciones maniobran una montée en généralité definida por Lafaye y Thévenot como "la capacidad a poner en relación cosas

\footnotetext{
${ }^{5}$ No es de nuestro interés en este artículo exponer los cuatro planes parciales que conforma el proyecto Nuevo Usme. Mencionamos tan solo este caso porque ejemplifica los resultados de la participación de las comunidades en la toma de decisiones sobre su territorio.

${ }^{6}$ La lucha popular contra la actividad de tres multinacionales (Cemex, Holguín y Fundacion San Antonio) ha sido dura y peligrosa, al punto que muchos de los líderes de Asamblea Sur - una organización que agrupa otras organizaciones- fueron amenazados durante un tiempo. En 2010, el Distrito de Bogotá decide suspender la actividad minera en el rio Tunjuelito, decisión que fue todo como un suceso para esta organización popular.
} 
particulares y entidades generales que caracterizan los instrumentos de justificación legitima que se forjan las comunidades políticas"(Lafaye C, 1993)

En Usme se identifican con mayor visibilidad dos tipos de argumentaciones por parte de las asociaciones. En primera medida, una argumentación ecológica y territorial que surge varias décadas atrás (anos 80 ), en el seno de organizaciones que inicialmente planteaban como eje central de sus acciones, el ordenamiento del territorio para las comunidades urbano-rurales del sur de la ciudad. Este tipo de discurso asociativo ha tenido la capacidad de vincular sus preocupaciones de orden local a preocupaciones mucho más globales como la defensa del medioambiente y el cambio climático. La otra argumentación es patrimonial, se consolida desde el hallazgo y reivindica el sustento cultural tanto material como ideal que existe en el territorio.

La construcción de estas argumentaciones participan de un proceso de patrimonialización que como lo expuso Guy di Méo está bien relacionado con el proceso de territorializacion. Así, "el territorio y el patrimonio tienen un contenido conceptual vecino: lo material y lo ideal, ellos participan juntos, estrechamente ligados, al fondo cultural de toda sociedad coherente, inscrita en el espacio" (Di Méo, 1994).

De ese modo, para lograr sus objetivos, los campesinos de Usme amenazados por la expansión han hecho emerger una identidad común -campesina-indígena-, a partir de los objetos arqueológicos encontrados en el hallazgo, en un área donde se había proyectado desarrollar el proyecto de viviendas. Este hecho, que generó un nuevo rumbo al conflicto vino a aportar nuevos argumentos de defensa del territorio. Así pues, con la llamada necrópolis de Usme se elaboró una sacralización de lugar que hasta ahora ha servido como argumento legítimo y poderoso para resolver el conflicto, toda una espacialidad simbólica (Debarbieux, 1995) que participa intensamente del proceso de territorializacion en Usme. De la misma manera, esta socialización del lugar sagrado ha conseguido fundamentar y mantener la acción colectiva hasta ahora desarrollada; por otro lado ha tenido el efecto de erigir un símbolo territorial con el que la población se identifica y en el que se reconoce el territorio. Como lo señala Michel Lussault la domesticación de la naturaleza y del patrimonio se apoya "sobre la revelación a un grupo social local de la existencia de un nuevo espacio de identidad y de legitimidad, lo que justamente los miembros denominan su territorio" (Lussault, 1995)

Al referirnos a este proceso de socialización del lugar, nos debemos referir también a la apropiación discursiva que el patrimonio arqueológico de Usme ha generado. Tal es el caso de los líderes comunitarios de las antiguas urbanizaciones que se ubican en la franja de conflicto. Ellos aparecen poco tiempo después del hallazgo como portadores de una reivindicación rural y una oposición al acecho desmesurado de la ciudad, exaltando los valores colectivos propios de la vida rural como la tranquilidad, la solidaridad y el sentido de pertenencia. Esta apropiación de la lucha campesina ahora hecha suya (es también de nosotros), viene a reforzar el trabajo asociativo que algunas organizaciones de carácter netamente urbano habían comenzado, 
trazándose dos objetivos claros: el primero, visibilizar las graves condiciones de habitabilidad de estas viviendas, la falta de equipamientos urbanos para una zona en crecimiento y por ende luchar por su consecución y mejoramiento. Como segundo objetivo, se trataba de buscar formas y mecanismos de integración y convivencia entre los que a principios del año 2000 llegaron a ser como afirmaba un viejo habitante del pueblo de Usme, "los primeros invasores" y los campesinos tanto del pueblo como los de la zona rural.

Si bien para algunas organizaciones como Audiencia Pública Popular y Usme-ando el Territorio, han legitimado su acción a través de la apropiación del discurso patrimonio -tradición que movilizan los campesinos, es el discurso medioambientalista en defensa del rio, que ha aportado un carácter más recio y ha forjado una identidad más compacta como movimiento. El rio para muchos de los habitantes representa como lo afirma a continuación este extracto de una grabación en el marco de una asamblea de vecinos un "paisaje y un ecosistema a defender, si traen más familias continuará contaminándose, en un futuro podría ser peligroso por el desbordamiento, el rio es de todos y debemos defenderlo" Entrevista Audiencia Pública, No 14)

El pasaje anterior refleja la coexistencia de dos discursos. Primero, el rio como un recurso-defensa vital para las comunidades tanto rurales como urbanas, partiendo de un argumento que concierne al orden ambiental y ecológico: su utilización, el acceso a este recurso, la contaminación... Desde este punto el conflicto del rio es considerado de interés general porque está ligado a la existencia de un bien común como el agua.

La cuestión de su cuidado y defensa se relaciona con un proceso que aborda otra escala geográfica mucho más amplio, el crecimiento de la ciudad. Lo anterior de nuevo ejemplifica otro espacio potencialmente creador de territorio, constructor de sentido social y configurador de territorialidad. El rio existe y está inserto dentro del paisaje cotidiano pero no es protegido, en ese sentido los habitantes lo instituyen como símbolo de lucha para su protección, pero para hacerlo simultáneamente un aliado de cara a los proyectos de vivienda.

Los "habitantes de lo urbano" han buscado entonces tener su incorporación en el seno de la red de asociaciones que tradicionalmente tienen un recorrido dentro de la arena política local. Ciertos de sus líderes han operado una estrategia de movilización que busca mantener la integración de los habitantes de las urbanizaciones, con la bandera del rio ondeando pero sin perder de vista el objetivo de detener el proceso de urbanización en una zona en donde a pesar de las múltiples formas de oposición "Todos los días sigue llegando gente al sector".

Esta segunda "invasión" de habitantes tiene un antecedente reciente. Inicia con la reubicación de las familias afectadas por la ola invernal ocurrida en Bogotá durante el año 2012, y posteriormente continua hasta nuestros días, con los programas de vivienda diseñados por el gobierno nacional para la reubicación de familias desplazadas y víctimas del conflicto. Ahora entran en contexto otros actores que añaden matices más complejos al conflicto, puesto que su 
llegada implica una serie de condiciones de aceptabilidad e integración para que el juego social continúe. Por el contrario, también puede implicar rechazo y una puesta en marcha de mecanismos de distanciamiento a través de prácticas y formas de vivir, en este espacio de proximidad en donde según algunos habitantes "se está construyendo una bomba de tiempo".

Este nuevo capítulo que se está empezando a escribir en la historia conflictual de Usme, resulta materia de reflexión por ser un revelador de nuevas territorialidades producidas por los actores, en ese sentido nos preguntamos igualmente qué consecuencias tendrán estas territorialidades en las dinámicas sociales subsecuentes

\section{Consideraciones finales}

Hemos presentado aquí los principales aportes de un estudio de caso en función de los efectos de un conflicto de proximidad generado por la expansión de la ciudad. Sin duda alguna lo más sorprendente del conflicto de Usme ha sido la intensidad de la oposición que ha conducido de manera particular a una gran capacidad de movilización y accionar de los habitantes. Como intentamos mostrarlo, estamos frente a un contexto de conflicto en donde la reacción dinámica y original de varios actores ha construido formas de valoración y apropiación del espacio que han justificado su legitimación y defensa.

De los ejemplos de apropiación y reapropiación que acabamos de ilustrar a través de nuestro conflicto, suponen una repolitización del espacio, una reconfiguración de la condición política de la ciudad y de la figura del ciudadano. En estos términos, podemos hablar en el sentido Lefebvriano de una apropiación de la ciudad como obra, como valor de uso, es decir una ciudad que se concibe como creación colectiva de los ciudadanos, como la actividad de un grupo que se apodera y se hace cargo de su papel y destino social (Lefebvre, 2013)

Estos procesos de territorializacion en Usme resultan significativos porque revelan la madurez de colectividades y organizaciones que han superado las primeras etapas de oposición y movilización, para llegar a instancias verdaderamente participativas y de concertación en donde se decide el posible avenir de los territorios. A medida que crece esta madurez asociativa, las asociaciones aprenden a jugar sobre diferentes frentes, se muestran particularmente receptivas a otras problemáticas que incorporan la cuestión territorial y van haciendo emerger espacios de negociación -el Borde sur- donde se crean las posibilidades de pesar sobre las decisiones. En oposición a una concepción de la participación a partir de acciones no institucionales, en Usme se ha forjado la constante interacción entre esfera institucional y participación, interacción que ha contribuido a la apropiación de no solo un lenguaje institucional por parte de los habitantes, sino de un lenguaje técnico y jurídico que en la actualidad muestra la implicación en el conflicto, pero a la vez la capacidad de intervención. Así pues, es necesario señalar el papel indispensable que juega este conjunto de conocimientos que en relación con el

(c) Urbana: Rev. Eletrônica Cent. Interdiscip. Estud. Cid $\quad$ Campinas (SP) $\quad$ v.8, n.3 [14] $\quad$ p.133-148 ISSN 1982-0569 
proceso de territorializacion, son significativos desde el punto de vista de su utilización; Estas herramientas hacen parte del lenguaje cotidiano tanto de líderes como de habitantes cuando se refieren a derechos de petición, artículos y normas. Así mismo, cuando se refieren a la definición de márgenes, bordes y polígonos o a derechos de propiedad y modos de ocupación del territorio.

De la misma manera, nuestro estudio de caso reveló la importancia de la dimensión simbólica - el hallazgo arqueológico- en la reivindicación de una identidad territorial. Cabe destacar que en Usme el nuevo espacio identitario ha emergido para unificar y legitimar una pluralidad de discursos en torno a la oposición de la expansión;

Por otro lado, el conflicto de Usme ha reactivado uno de los dilemas fundamentales no solo de Bogotá sino del país, es decir el uso y la tenencia de la tierra o el suelo. Junto a este dilema el conflicto Usmeno replantea el modelo de ciudad que los ciudadanos desean, en búsqueda de una nueva realidad espacial (Lefebvre, 2013), o por el contrario una ciudad concebida desde un ámbito urbanístico-inmobiliario, acompasado por las leyes y normas de quienes diseñan su política. Así mismo, es a través del conflicto que se revela la capacidad de los ciudadanos para poner en marcha acciones colectivas que buscan repensar la relación sociedad-espacio, con el objetivo de construir ciudades cada día más democráticas e incluyentes.

\section{Bibliografía}

- Abad Faciolince, Hector. Angosta Editorial Planeta, Colección letras colombianas de hoy, 2004.

- Alfonso Roa, Oscar. Bogotá segmentada Reconstrucción histórico social de la estructuración residencial de una metrópoli latinoamericana. Editorial Universidad del Externado, Bogotá 2012.

- Bourdin et Melé en Conflictos de proximidad y dinámicas urbanas, bajo la dirección de Patrice Melé, Editorial Presses Universitaires de Rennes, 2013.

- Debarbieux, Bernard. Le lieu, le territoire et trois figures de rhétorique. Revista L'espace geographique, Volumen 2 No 24, 1995.

- Di Méo, Guy. Patrimoine et territoire une parenté conceptuelle. Revista Espaces et Sociétés, No 4, Editorial Eres, Paris, 1994.

- Harvey, David. La condicicion posmoderna. Editorial Amorrortu, Madrid, 1993.

- Lafaye C. Et Thévenot L. «Une justification écologique ? Conflits dans I'aménagement de la nature », Revista Francesa de sociologia, No 4, 1993.

- Lefebvre, Henri. La produccion del espacio. Capitan swimg Libros, colección entrelíneas, Madrid, Noviembre 2013. 
- Lulle, Thierry. Bogotá : croissance, gestion urbaine et démocratie locale in Dureau F. et al. Villes et sociétés en mutation - lectures croisées sur la Colombie, Paris : Anthropos, 2004.

- Lussault, Michael. « L'objet environnemental dans I'action territoriale », Revista Montagnes méditerranéens, No 1 / 1995

- Romero, Jose Luis. Las ciudades y las ideas. Siglo XXI Editores s.a. Argentina, primera reimpresión, 1986.

- Simmel, George, Le conflit, Editorial Circé, collection No 3, Paris 1998

- http://www.bogotaturismo.gov.co/agroparque-los-soches 